\title{
Queue Tree Implementation for Bandwidth Management in Modern Campus Network Architecture
}

\author{
Rifki Indra Perwira ${ }^{*}$, Febri Liantoni ${ }^{2}$ \\ 1UPN "Veteran" Yogyakarta, ${ }^{2}$ Institut Adhi Tama Surabaya \\ rifki@upnyk.ac.id ${ }^{*}$, febri.liantoni@gmail.com²
}

\begin{abstract}
Bandwidth management in an institution becomes a fundamental need that must be managed properly. The continuous increase in the number of user, data and hardware technologies result in unequal distribution and bandwidth absorption. The increasingly diverse needs of the users in the virtual world require refined setting of bandwidth scheme. If bandwidth is not set properly, bandwidth can be accessed by multiple users. Institutions engaged in education consist of several parties such as employees, teachers and students (called student body). Queue implementation is a technique of dividing bandwidth according to the proportional needs of its users; moreover, this technique is able to work flexibly to organize and allocate bandwidth to end users. The ease of adding and reducing the amount of bandwidth becomes its main feature. The concept of campus network adopted from a Cisco fundamental system can serve as one model that can optimize the infrastructure and the distribution of bandwidth to end users. The method used in this research is employing direct observation, conducting interviews for problem identification and assigning the Internet service requirement and the availability of hardware and software resources. The optimization of bandwidth management by considering student body becomes the main objective. The implementation of queue on each network allows the distribution of bandwidth conforming the user satisfaction. Based on user satisfaction survey result, the user satisfaction level of Queue Tree implementation reached 59.2\%.
\end{abstract}

Keywords: Bandwidth, Queue, Campus Network, The Internet, Cisco Fundamental System

\section{Introduction}

\subsection{Background}

Internet related needs have become a primary and fundamental demands for human beings. Syarifuddin [1] stated that one of the three students and professionals considered the Internet to be as important as water, air, shelter, and food, explaining the requirement of bandwidth, especially the Internet, is very important in their life. Furthermore, the increasing requirement and utilization of Internet technology causes the demand in a large bandwidth allocation by its users to support all activities in cyberspace.

The users' demand to get uninterruptable and fast Internet access should be viewed from the aspect of bandwidth volume subscribed to an institution. Although the Internet has become a fundamental need like air, water, food, and shelter, its provision is still considered very expensive.

The Internet has a pivotal role in various fields including in educational institutions. Various services and flexibility provided by bandwidth can certainly facilitate business and transaction processes in an educational institution. In addition, the Internet is also utilized to obtain the latest updates of research journal and community services as well as to publish the results of its publication. With the increasing number of resources and the rapid growth of smartphone users with various supporting applications, indirectly leading to bandwidth requirement increase.

Bandwidth, when simultaneously used by a large number of users, will experience declining ability impacting the quality of service commonly considered as undesirable. In this case, of course, good management in bandwidth allocation will be required. If there are no bandwidth rules or management, some users may abuse or dominate bandwidth usage by downloading large files. While other users browsing the Internet will experience longer period in accessing and opening sites. In addition to optimizing bandwidth management, arrangements need to be executed to support higher education activities exemplified by uploading or downloading related academic materials such as journals, research reports and community services.

Liantoni, F., \& Perwira, R. (2017). Queue Tree Implementation for Bandwidth Management in Modern Campus Network Architecture. Kinetik : Game Technology, Information System, Computer Network, Computing, Electronics, and Control, 3(1). http://dx.doi.org/10.22219/kinetik.v3i1.227

Paper submitted on June 11, 2017; Revision on 26 July, 2017; Received July 31, 2017 
Limiting the bandwidth volume to the end users and performing balanced bandwidth become two most favorable advantages. Bandwidth will automatically set up and down based on the number of active users. Therefore, the need to study queue implementation for bandwidth management at educational institutions implemented in modern campus network architecture is vital.

\subsection{Literature Review}

A relevant research on this topic has been done by Gunawan entitled Queue Tree Implementation for Optimizing Bandwidth Management on Seven Net Semarang [2]. Bandwidth management is a process of measuring and controlling communications (traffics and packets) on a network link, to avoid overfilling links. Establishing appropriate allocation or bandwidth setting using a MikroTikPC router becomes the main purpose of this study. Bandwidth management provides the ability to manage network bandwidth and provide services according to the customers' needs and priorities. The methods used are Queue Tree and Per Connection Queue. The research steps cover analyzing the old system, making priority scale and configuring MikroTik. From the result of tests conducted on the implementation of Bandwidth Management using MikroTik, satisfactory results are obtained. In detail, the bandwidth obtained by the three PC testers has similar average bandwidth amount, approximately $300 \mathrm{kbps}$, showing evenly distributed bandwidth.

Another study conducted by Wibowo [3] discussing the optimization of Internet bandwidth management using RB450G router took the case at the forest research development office. In his research, Wibowo used an observation method by having direct observation, conducting interview for problem identification and finding the needs of Internet services and the availability of hardware and software resources. Moreover, questionnaires were used to acquire the users' perception in the office area as well as the evaluation of the results of the implementation of Internet bandwidth management optimization. The result of this research is the improvement of the priority level obtained from the comparison of service quality parameters before and after optimization. Some differences are recognized: having an increase of download speed as much as $0.03 \mathrm{Mbps}$, $4.05 \mathrm{Ms}$ smaller latency, smaller packet loss by $2.21 \%$. Meanwhile, the results of the questionnaire showed $65 \%$ of users quite satisfied with the results of after bandwidth optimization.

Based on Darmawan's study entitled The Bandwidth Management Queue Tree vs. Simple Queue, some parameters such as delay, jitter, packet loss and throughput are calculated [4]. The result shows greater throughput than bandwidth management using Queue Tree. The delay generated from using Simple Queue is greater than using Queue Tree. Average jitter between Simple Queue and Queue Tree does not show significant differences. Simple Queue feature generates a larger percentage of packet loss than that of Queue Tree. There are several things affecting the results of this experiment, including the algorithm used in the Simple Queue and Queue Tree that affects the throughputs from both methods. Furthermore, the protocol used in experimental scenarios in this case is ICMP protocol suggesting to the existing delays. Moreover, UDP protocol is also employed leading to data jitter and packet loss being connectionless oriented. This study also employed software and the creation of computer network topology.

Hizbullah conducted a study entitled Bandwidth Management using RB750 with Queue Tree Method with Various Priority Levels and Testing Pornographic Content Filtering and Pornography Using DNS Newsletter [5]. This research uses stress test method. Stress testing is executed by accessing some web addresses that have been filtered by MikroTik on the computer provided in a cafe either by using browsers or by using additional programs. Testing bandwidth management is performed by downloading data simultaneously using multiple computers. The results showed that the pornography and porno-action related contents can be more optimally filtered, but the configuration becomes more complicated.

\subsection{Theory}

\subsubsection{Computer Network}

Computer networking, being a computer and communication technology with a single computer model serving all the computational tasks of an organization, has now been replaced with a collection of separate computers but are interconnected in performing their tasks [6]. Computer networks allow the utilization of shared computer equipment of various brands, which 
originally spread in various rooms, units, and departments so as to increase the effectiveness of resources used.

\subsubsection{Bandwidth}

According to Williams and Stacey, the definition of bandwidth is the frequency, range, or band (bandwidth of the transmission medium) carried over a period of time [7]. In general, there are two bandwidth types, narrow bandwidth and broad bandwidth, which can be expressed both in hertz and also in bits per second (bps). Although the current Indonesian price of Internet bandwidth is getting cheaper, the price generally can be considered as still quite expensive. Hence, bandwidth leasing rates cannot be said cheap. The greater the volume of bandwidth also affects the greater the cost incurred. Therefore, bandwidth subscribed by an institution needs to be arranged in more effective and efficient way. In other words, similar to a large highway passed by various kinds and great number of vehicles (vehicle = data), the bigger the road, the more vehicles can be accommodated. Conversely, a smaller road with a big number of vehicles will easily experience a bottleneck.

\subsubsection{Queue Tree}

Queue Tree is a menu on routers to perform bandwidth management for complex network scenarios [3]. The Queue Tree configuration is a one-way queue configuration meaning that a queue configuration will only be able to queue 1 (one) way traffic type of download or upload traffic only. Thus, to control traffic download and upload traffic, it takes 2 (two) queue configurations. The top-down and the bottom-up principle of executing queue configurations cannot be applied to the Queue Tree because the queue configuration will be executed simultaneously, leading to the sequence configuration in this menu having no effect on the desired bandwidth management results.

\subsubsection{Campus Network}

Parquet and Teare in a book entitled Campus Network Design Fundamentals said the design of the campus network hierarchy is also called Cisco hierarchical design describing a network map being smaller (cluster) and more manageable [8]. Each level or layer in the modern campus network hierarchy is focused on a specific role. By separating the existing various functions on the network, the network design becomes modular so as to facilitate scalability and performance. In turns, this helps the network design or network architect to optimize and select the suitable hardware. The campus network hierarchy can be seen in Figure 1.

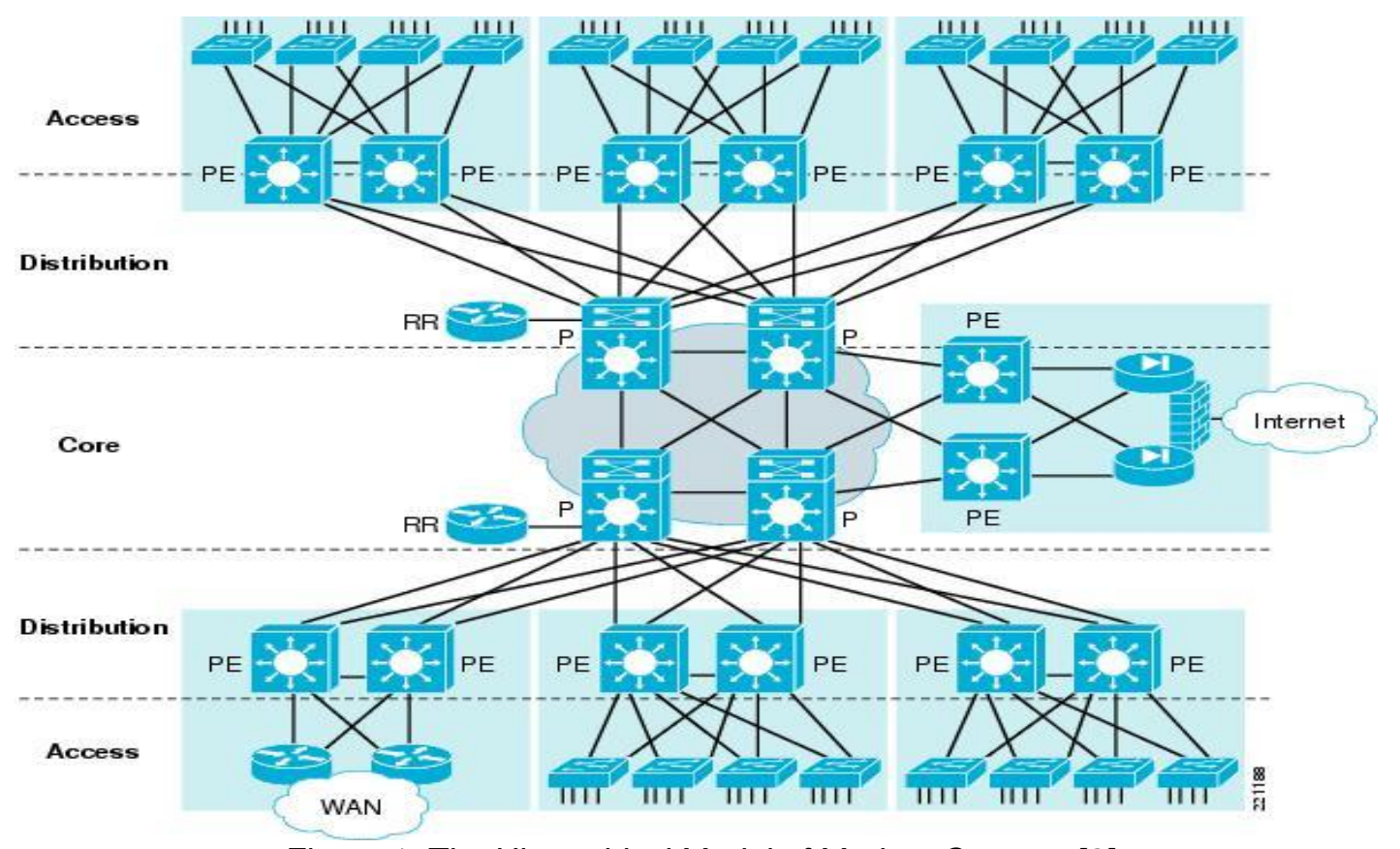

Figure 1. The Hierarchical Model of Modern Campus [8] 


\section{Research Methods}

The method used in this research covers literature study and SDLC (System Development Life Cycle) methodology of a computer network model which includes Planning, Analysis, Design, Implementation, Support [9], while the research flow is presented in Figure 2. At The research undertaken referred to the configuration of the research that was done earlier in 2015 [10]. The implementation is also carried out survey results of implementation to determine the level of satisfaction.

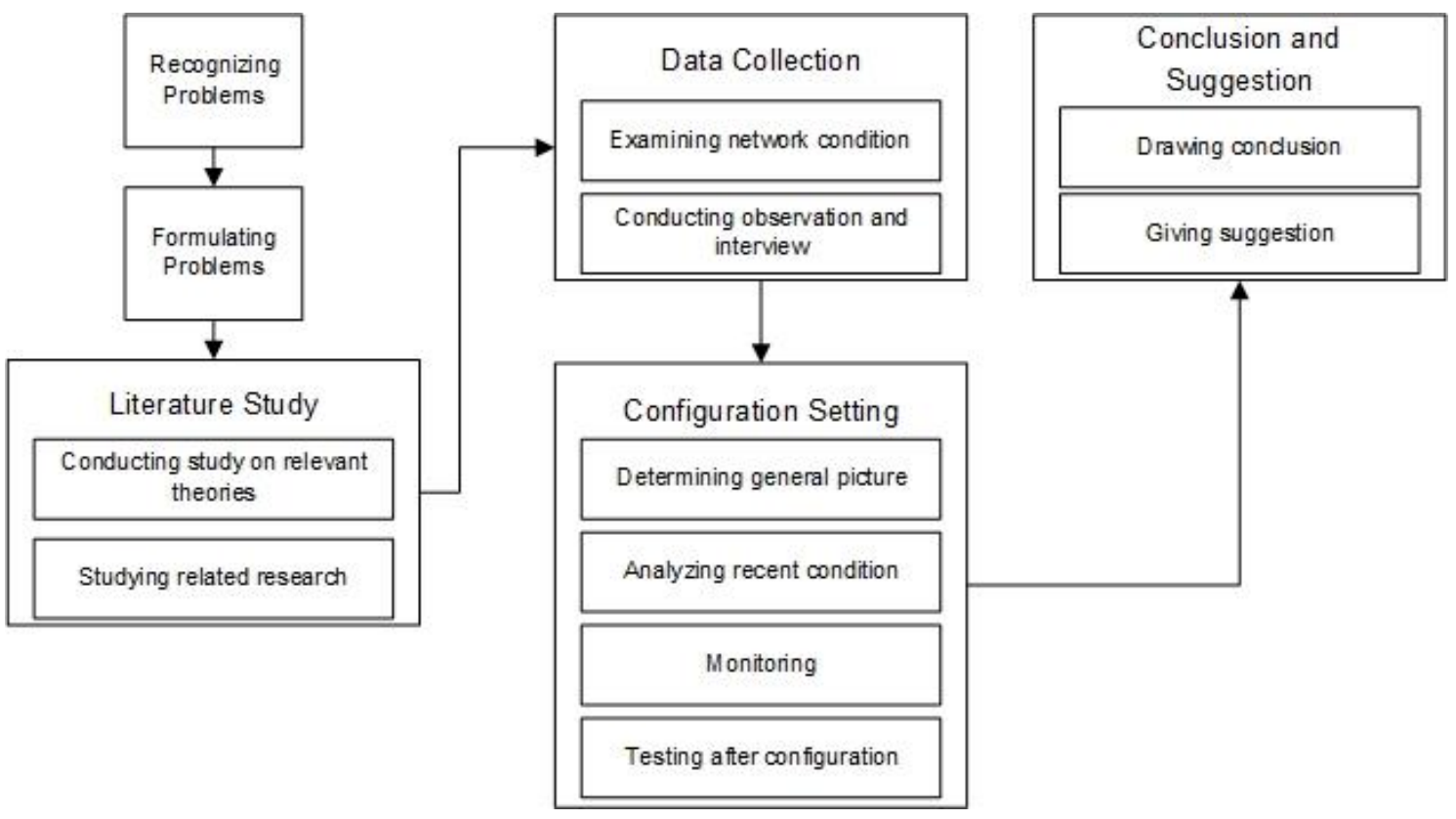

Figure 2. Research Flow

The flow of this research covers two parts, primary materials and secondary materials. Primary materials consist of (1) document management of network infrastructure; and (2) data obtained directly from the object, the results of observation, and interviews. Meanwhile, the secondary materials are obtained from related literature and previous research.

\section{Results and Discussion}

\subsection{Topology}

Campus network has three layers consisting of core, distribution, and access. The core layer is the topmost layer dealing directly with the Internet as an internal gateway. Distribution layer is a layer being in the middle of the core layer and access layer distributing the packets based on broadcast domains that have been configured by the network administrator. Meanwhile, the access layer is a layer located playing the part as a dealer access to the end user.

The position of MikroTik management bandwidth is located under the access switch for each department and under the main router for central management. This research using topology that shown in Figure 3.

\subsection{Volume Bandwidth}

Bandwidth allocation was adjusted according to the student body's volume and priority. This arrangement was applied to maintain equity based on the volume of bandwidth subscribed. The division of bandwidth based on the student body is illustrated by Table 1 .

\subsection{Queue Tree}

Bandwidth distribution was managed using Queue Tree having more complicated implementation because of separate upload and download functions. The implementation of bandwidth distribution was arranged based on faculty and then managed in detail based on its majors. This division was based on the student body that had been implemented in the previous 
stage or based on specific request according to the requirement of certain events. The following Figure 4 shows the download Queue Tree view for each department.

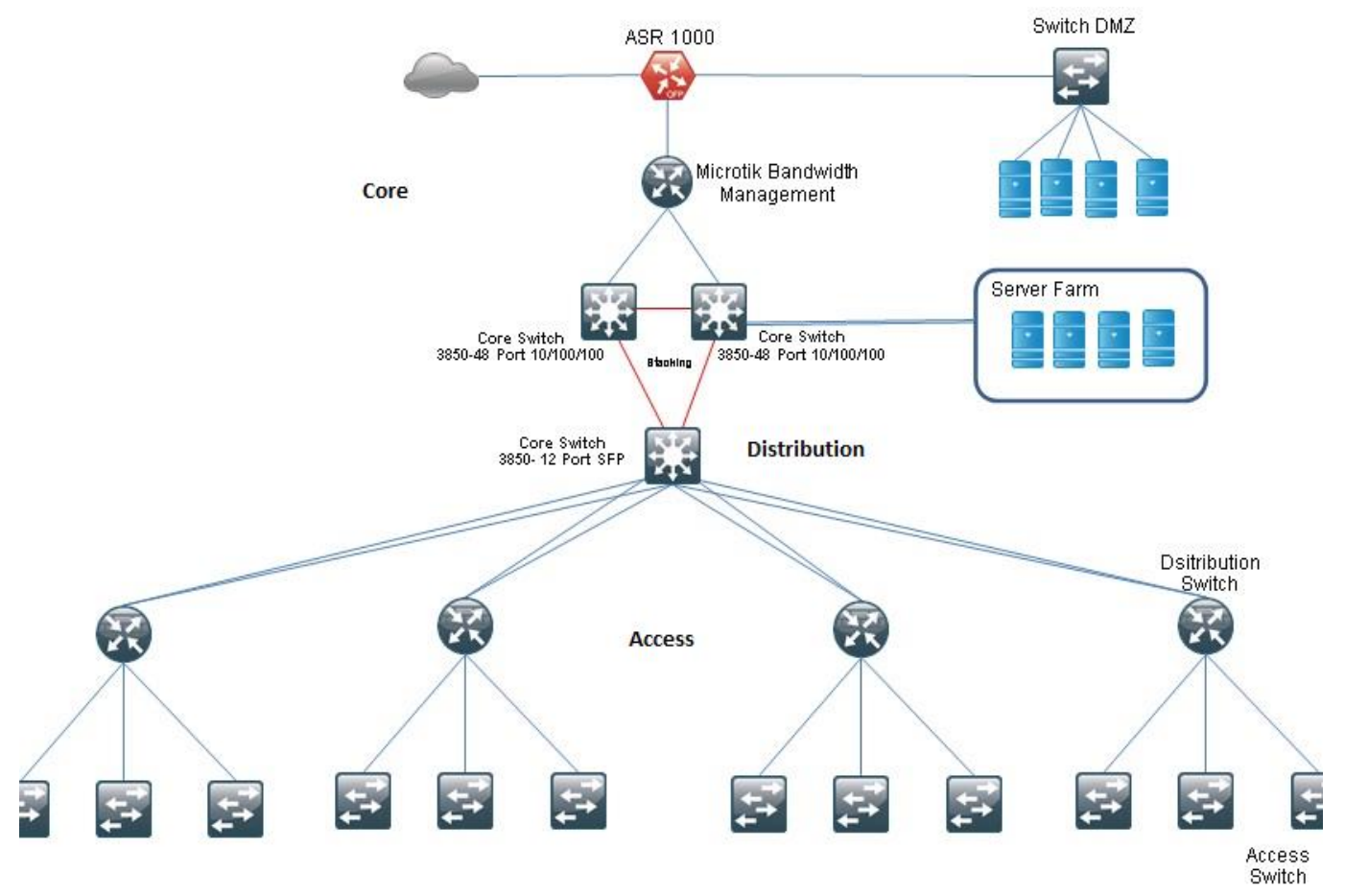

Figure 3. Topology Used [10]

Table 1. Bandwidth Distribution

\begin{tabular}{|c|c|c|c|}
\hline No & Study Program & $\begin{array}{l}\text { Student } \\
\text { Body }\end{array}$ & BW(Kbps) \\
\hline 1. & Agrotechnology & 695 & 10000 \\
\hline 2. & Agrobusiness & 516 & 4000 \\
\hline 3. & Management & 1808 & 14888 \\
\hline 4. & Economic development & 336 & 3696 \\
\hline 5. & Accounting & 984 & 10824 \\
\hline 6. & International Relations & 753 & 8283 \\
\hline 7. & $\begin{array}{c}\text { Business } \\
\text { Administration }\end{array}$ & 520 & 5720 \\
\hline 8. & Communication & 1027 & 3000 \\
\hline 9. & Geological Engineering & 809 & 3000 \\
\hline 10. & Mining Engineering & 825 & 9075 \\
\hline 11. & Petroleum Engineering & 744 & 8184 \\
\hline 12. & $\begin{array}{l}\text { Environment } \\
\text { Engineering }\end{array}$ & 530 & 5830 \\
\hline 13. & $\begin{array}{l}\text { Geophysical } \\
\text { Engineering }\end{array}$ & 360 & 3960 \\
\hline $\begin{array}{l}14 . \\
15 .\end{array}$ & $\begin{array}{l}\text { Chemical Engineering } \\
\text { Industrial Engineering }\end{array}$ & $\begin{array}{l}921 \\
665\end{array}$ & $\begin{array}{c}10131 \\
7315\end{array}$ \\
\hline 16. & $\begin{array}{l}\text { Informatics } \\
\text { Engineering }\end{array}$ & 727 & 14000 \\
\hline $\begin{array}{l}17 . \\
18 .\end{array}$ & $\begin{array}{l}\text { D3 Chemistry } \\
\text { Rectorate }\end{array}$ & $\begin{array}{c}172 \\
50\end{array}$ & $\begin{array}{c}1892 \\
31000\end{array}$ \\
\hline 19. & $\begin{array}{l}\text { Other Technical } \\
\text { Implementation Units } \\
\text { Information and }\end{array}$ & 100 & 31000 \\
\hline 20. & $\begin{array}{l}\text { Communication } \\
\text { Technologies }\end{array}$ & 20 & 20000 \\
\hline
\end{tabular}




\begin{tabular}{|c|c|c|c|c|}
\hline 昰 01-00-Down-ALL & global-out & & & \\
\hline 을 01-01-Down-FTM & 01-00-Down-ALL & & & \\
\hline 狚 112.5 & 01-01-Down-FTM & Down_112.5 & $1 \mathrm{M}$ & $1 \mathrm{M}$ \\
\hline 恶 Download-110-dekanat & 01-01-Down-FTM & down_110 & $12 \mathrm{k}$ & $12 \mathrm{k}$ \\
\hline 車 Download-112-Dekan-FTM & 01-01-Down-FTM & down_112 & $1 \mathrm{M}$ & $5 \mathrm{M}$ \\
\hline 是 Download-120-Tambang & 01-01-Down-FTM & down_120 & $1 \mathrm{M}$ & $9075 \mathrm{k}$ \\
\hline B Download-130-Geologi & 01-01-Down-FTM & down_130 & $3 \mathrm{M}$ & $8899 k$ \\
\hline B Download-140-Minyak & 01-01-Down-FTM & down_140 & $1 \mathrm{M}$ & $8184 \mathrm{k}$ \\
\hline 을 01-02-Down-FE & 01-00-Down-ALL & & & \\
\hline 是 Down_POLIKLINIK & 01-02-Down-FE & Down_POLIKLINIK179 & $5 \mathrm{M}$ & $10 \mathrm{M}$ \\
\hline 皘 Download-150-dekanat ekonomi & 01-02-Down-FE & down_150 & $1 \mathrm{M}$ & $1 \mathrm{M}$ \\
\hline 軍 Download-160-Auditorium & 01-02-Down-FE & down_160 & $512 \mathrm{k}$ & $1 \mathrm{M}$ \\
\hline B Download-170-Akutansi & 01-02-Down-FE & down_170 & $3 \mathrm{M}$ & $10 \mathrm{M}$ \\
\hline Download-180-Pascasarjana & 01-02-Down-FE & down_180 & $1 \mathrm{M}$ & $3696 \mathrm{k}$ \\
\hline Download-190-Manajemen & 01-02-Down-FE & down_190 & $5 \mathrm{M}$ & $15 \mathrm{M}$ \\
\hline 䓃 Lab Manajemen & 01-02-Down-FE & down_199 & $1 \mathrm{M}$ & $1 \mathrm{M}$ \\
\hline 是 Lab Pembangunan & 01-02-Down-FE & down_188 & $1 \mathrm{M}$ & $1 \mathrm{M}$ \\
\hline 軍 Lab akutansi & 01-02-Down-FE & down_177 & $1 \mathrm{M}$ & $10 \mathrm{M}$ \\
\hline 绎 R.Seminar & 01-02-Down-FE & down_170_R.Seminar & $1 \mathrm{M}$ & $1 \mathrm{M}$ \\
\hline 을 01-03-Down-FP & 01-00-Down-ALL & & & \\
\hline 是 Download-104-MMA & 01-03-Down-FP & down_104 & $1 \mathrm{M}$ & $5 \mathrm{M}$ \\
\hline 軍 Download-60-Dekan-FP & 01-03-Down-FP & down_60 & $1 \mathrm{M}$ & $3 \mathrm{M}$ \\
\hline B Download-70-Sosek (Trouble hardw) & 01-03-Down-FP & down_70 & $10 \mathrm{k}$ & $10 \mathrm{k}$ \\
\hline 軎 Download-80-MAN,SDL & 01-03-Down-FP & down_80 & $2 \mathrm{M}$ & $4 \mathrm{M}$ \\
\hline 軍 Download-90-Agro & 01-03-Down-FP & down_90 & $3 \mathrm{M}$ & $10 \mathrm{M}$ \\
\hline 量 Download-91-Geofisika & 01-03-Down-FP & down_91 & $1 \mathrm{M}$ & $3960 \mathrm{k}$ \\
\hline 䓃 Download-92-TL & 01-03-Down-FP & down_92 & $1 \mathrm{M}$ & $3 \mathrm{M}$ \\
\hline R.seminar FP & 01-03-Down-FP & down_seminar & $1 \mathrm{M}$ & $1 \mathrm{M}$ \\
\hline 是 Wifi lahan & 01-03-Down-FP & Down_81 & $512 \mathrm{k}$ & $512 \mathrm{k}$ \\
\hline 을 01-04-Down-FISIP & 01-00-Down-ALL & & & \\
\hline 是 Download-210-Dekan-FISIP & 01-04-Down-FISIP & Down_210 & $1 \mathrm{M}$ & $2 \mathrm{M}$ \\
\hline 经 Download-211-Komunikasi & 01-04-Down-FISIP & down_211 & $3 \mathrm{M}$ & $3 \mathrm{M}$ \\
\hline 夏 Download-212 & 01-04-Down-FISIP & down_212 & $1 \mathrm{M}$ & $1 \mathrm{M}$ \\
\hline 是 Download-214-AB & 01-04-Down-FISIP & down_214 & $1 \mathrm{M}$ & $5720 \mathrm{k}$ \\
\hline E Download-215-PembayaranBBS & 01-04-Down-FISIP & down_215 & $600 \mathrm{k}$ & $800 \mathrm{k}$ \\
\hline
\end{tabular}

Figure 4. Queue Tree Download

Table 1 becomes the reference of bandwidth required for each department. At the time of implementation, it does not have to follow the figures in Table 1. The implementation requirements were adjusted to the conditions in the field. The Queue Tree download is used to filter activity of a bandwidth quantity during download activity. Figure 5 below presents the Queue Tree upload view.

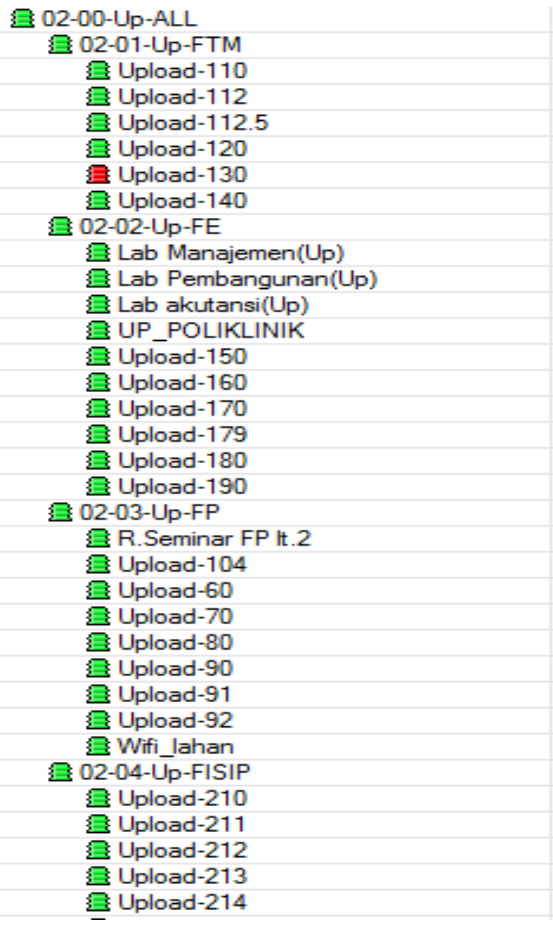

\begin{tabular}{|c|c|c|c|}
\hline \\
\hline \multicolumn{4}{|l|}{$\begin{array}{l}\text { global-in } \\
02-00-\text { Up-ALL }_{\text {p }}\end{array}$} \\
\hline 02-01-Up-FTM & up_110 & $1 \mathrm{M}$ & $5 \mathrm{M}$ \\
\hline 02-01-Up-FTM & up_112 & $1 \mathrm{M}$ & $5 \mathrm{M}$ \\
\hline 02-01-Up-FTM & up_112.5 & $1 \mathrm{M}$ & $5 \mathrm{M}$ \\
\hline 02-01-Up-FTM & up_120 & $1 \mathrm{M}$ & $5 \mathrm{M}$ \\
\hline 02-01-Up-FTM & up_130 & $1 \mathrm{M}$ & $5 \mathrm{M}$ \\
\hline 02-01-Up-FTM & up_140 & $1 \mathrm{M}$ & $5 \mathrm{M}$ \\
\hline \multicolumn{4}{|l|}{ 02-00-Up-ALL } \\
\hline $02-02-U p-F E$ & Up_199 & $1 \mathrm{M}$ & $5 \mathrm{M}$ \\
\hline $02-02-U p-F E$ & up_188 & $1 \mathrm{M}$ & $5 \mathrm{M}$ \\
\hline $02-02-U p-F E$ & up_177 & $1 \mathrm{M}$ & $5 \mathrm{M}$ \\
\hline $02-02-U p-F E$ & Up_POLIKLINIK179 & $5 \mathrm{M}$ & $10 \mathrm{M}$ \\
\hline $02-02-U p-F E$ & up_150 & $1 \mathrm{M}$ & $5 \mathrm{M}$ \\
\hline $02-02-U p-F E$ & up_160 & $1 \mathrm{M}$ & $5 \mathrm{M}$ \\
\hline $02-02-U p-F E$ & up_170 & $1 \mathrm{M}$ & $5 \mathrm{M}$ \\
\hline $02-02-U p-F E$ & upload_179poli & $1 \mathrm{M}$ & $5 \mathrm{M}$ \\
\hline $02-02-U p-F E$ & up_180 & $1 \mathrm{M}$ & $5 \mathrm{M}$ \\
\hline $02-02-U p-F E$ & up_190 & $1 \mathrm{M}$ & $5 \mathrm{M}$ \\
\hline \multicolumn{4}{|l|}{ 02-00-Up-ALL } \\
\hline 02-03-Up-FP & up_seminar & $1 \mathrm{M}$ & $5 \mathrm{M}$ \\
\hline $02-03-U_{p}-F P$ & up_104 & $1 \mathrm{M}$ & $5 \mathrm{M}$ \\
\hline $02-03-U p-F P$ & up_60 & $1 \mathrm{M}$ & $5 \mathrm{M}$ \\
\hline 02-03-Up-FP & up_70 & $1 \mathrm{M}$ & $5 \mathrm{M}$ \\
\hline $02-03-$ Up-FP & up_80 & $1 \mathrm{M}$ & $5 \mathrm{M}$ \\
\hline 02-03-Up-FP & up_90 & $1 \mathrm{M}$ & $5 \mathrm{M}$ \\
\hline 02-03-Up-FP & up_91 & $1 \mathrm{M}$ & $5 \mathrm{M}$ \\
\hline 02-03-Up-FP & up_92 & $1 \mathrm{M}$ & $5 \mathrm{M}$ \\
\hline 02-03-Up-FP & & $1 \mathrm{M}$ & $5 \mathrm{M}$ \\
\hline \multicolumn{4}{|l|}{ 02-00-Up-ALL } \\
\hline 02-04-Up-FISIP & up_210 & $1 \mathrm{M}$ & $5 \mathrm{M}$ \\
\hline 02-04-Up-FISIP & up_211 & $1 \mathrm{M}$ & $15 \mathrm{M}$ \\
\hline 02-04-Up-FISIP & up_212 & $1 \mathrm{M}$ & $3 \mathrm{M}$ \\
\hline 02-04-Up-FISIP & up_213 & $1 \mathrm{M}$ & $3 \mathrm{M}$ \\
\hline 02-04-Up-FISIP & up_214 & $1 \mathrm{M}$ & $5 \mathrm{M}$ \\
\hline
\end{tabular}

Figure 5. Queue Tree Upload 


\subsection{Bandwidth Configuration}

The bandwidth reconfiguration procedure can be executed for policy reasons. The policy provides 2 Kbps for each student based on the student body and SLA (Service Level Agreement) subscribed. This volume is considered still very far from ideal. Thus, it should be increased in the future in enhancing services to academic community. In increasing and reducing the bandwidth can be executed using WinBox software as illustrated in Figure 6.

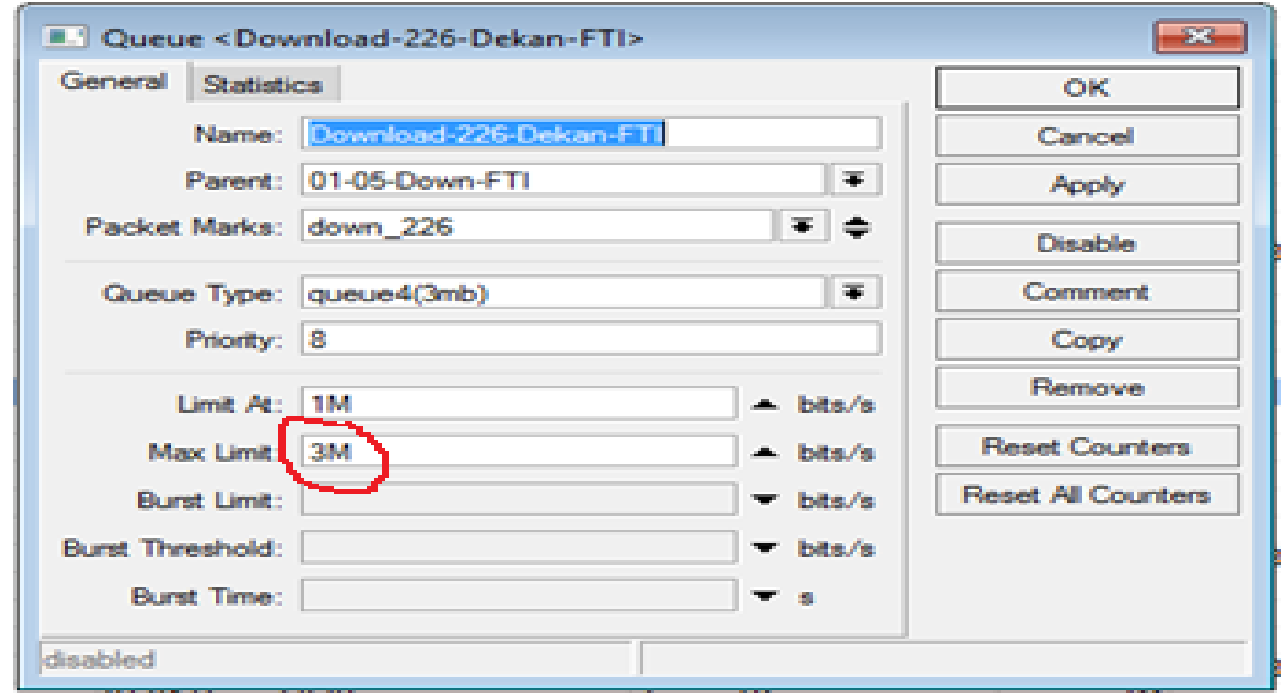

Figure 6. The Bandwidth Reconfiguration

In Figure 6, for example, the Faculty of Industrial Engineering Department with an initial position is given a minimum limit at 1 Mbps and the maximum limit of 3 Mbps. To change the volume of bandwidth to suit the needs, the users can press the triangle mark symbol next to it and change the desired number. The limit at $1 \mathrm{M}$ means that the minimum bandwidth received by the FTI study program is $1 \mathrm{Mbps}$ while for Max Limit (highest limit) is configured at $3 \mathrm{Mbps}$. These numbers can be reconfigured to suit specific needs and conditions.

\subsection{Test Results}

The results of the test speed present good operation of the bandwidth implemented in the previous stage. For example, the speed test using an Internet connected notebook executed on Friday, June 2, 2017 can be seen in Figure 7.

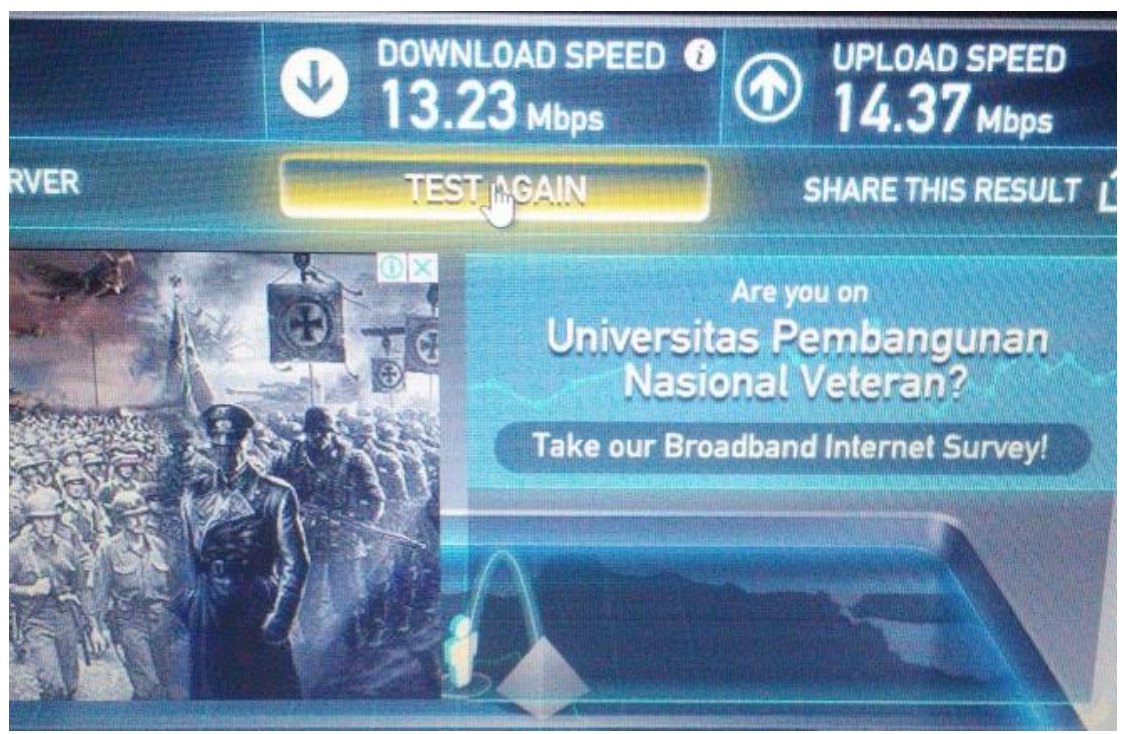

Figure 7. The Test Results Using speedtest.net 
Figure 7 shows the results of the download speed test using the URL http://speedtest.net. The test was executed in Informatics Engineering Department which previously had configured its bandwidth on MikroTik with a volume of $14 \mathrm{Mbps}$ (referring to Table 1). Figure 7 illustrates the speed test findings by 13.23 Mbps download speed and 14.37 Mbps upload speed. The references [10] suggest MikroTik has the ability not only to optimize bandwidth usage but also to manage bandwidth in maintaining its efficiency [6], proven by a few wasted packets.

\subsection{User Satisfaction Result}

From the series of research stages that had been completed according to Figure 2, the last research flow was tested after setting configuration. After the test configuration was finished in two ways using the speedtest.net tool (Figure 7) and using the satisfaction survey (Table 2), the satisfaction survey was conducted to determine the level of user satisfaction with more evenly bandwidth management using the queue based on the student body. This survey takes form of questions completed by the users with four assessment parameters, ranging from Very Satisfied, Satisfied/Good, Fair and Not Satisfied.

Three assessed questions that should be responded by the users are as follows:

1. How is the speed of Internet access on an important application?

2. How is the quality of the Internet network services perceived after being managed?

3. How is the appropriacy of bandwidth distribution based on the student body?

The results of this survey are presented in Table 2 .

Table 2. User Satisfaction Result

\begin{tabular}{cccccc}
\hline \multirow{2}{*}{ No } & Questions & $\begin{array}{c}\text { Very } \\
\text { Satisfied }\end{array}$ & Satisfied & Fair & $\begin{array}{c}\text { Not } \\
\text { Satisfied }\end{array}$ \\
\hline 11 & $\begin{array}{c}\text { The speed of Internet access } \\
\text { to access applications } \\
22\end{array}$ & $5(5 \%)$ & $65(65 \%)$ & $20(20 \%)$ & $10(10 \%)$ \\
$\begin{array}{c}\text { The quality of Internet } \\
\text { network service after being } \\
\text { managed }\end{array}$ & $2(2 \%)$ & $58(58 \%)$ & $25(25 \%)$ & $15(15 \%)$ \\
33 & $\begin{array}{c}\text { The bandwidth distribution } \\
\text { based on student body }\end{array}$ & $0(0 \%)$ & $55(55 \%)$ & $25(25 \%)$ & $20(20 \%)$ \\
\hline & Average & $3.5 \%$ & $59.2 \%$ & $23.3 \%$ & $15 \%$ \\
\hline
\end{tabular}

Based on Table 2, the results of user satisfaction on the implementation of this queue prompt by $59.2 \%$ Good or Satisfied responses and $15 \%$ of Unsatisfied feedbacks.

\section{Conclusion}

The conclusions of this study are as follows:

1. The level of user satisfaction is $59.2 \%$.

2. The ability to provide more flexible bandwidth uptake by configuring MikroTik leading to small packet loss.

3. The distribution of bandwidth volume based on the student body has not provided overall user satisfaction.

\section{References}

[1] Syarifuddin, D., "Air, Food, Water, Internet - Cisco Study Revealing the Significant Importance of Internet and Network as the Common Man Needs," 2011, Quoted from http://www.jagatreview.com/2011/09/pr-udara-makanan-air-Internet-\%E2\%80\%93penelitian-cisco-mengungkapkan-betapa-pentingnya-Internet-dan-jaringan-sebagaikebutuhan-mendasar-dalam-kehidupan-sehari-hari/ accessed on May 1, 2017, on 09.00.

[2] Gunawan, A., B., "The Implementation of Queue Tree to Optimize Bandwidth management on Seven Net Semarang," 2014, quoted from http://eprints.dinus.ac.id/13489/2/abstrak_14171.pdf / accessed on Mei 5, 2017, on 13.30.

[3] Wibowo, E., "Bandwidth management Optimization using MikroTik RB450G (A Case Study at the Office of Center for Biotechnology Research and Forest Plant Breeding (BBPBPTH)," 2014, Universitas Gadjah Mada.

KINETIK Vol. 3, No. 1, February 2018: 17-26 
[4] Darmawan, E., Purnama, I., Mahardika, T., I., R. "Bandwidth Manajemen Queue Tree vs. Simple Queue," National Conference of Information System, STMIK-STIKOM Bali, 23-25 Februari 2012.

[5] Hizbullah, A., "Bandwidth and Network Security Optimization with Filtration on Internet Café Using MikroTik Routerboard," Computation Journal, Vol. 1, No. 1, Pp. 14, Pp. 103 - 116, December 2012.

[6] Tanenbaum, A., S., "Computer Network," 5th edition, Prentice Hall, 2010.

[7] William, K., B., Stacey, C., S., "Using Information and Technology - A Practical Introduction to Computers \& Communications," Vol. 9E, 2009.

[8] Teare, D., \& Paquet, C., "Campus Network Design Fundamentals," eBook cisco, Cisco Press, 2005.

[9] Baras, J., \& Shah, P., "Developing Network Fault Management System using SDLC Methodology," University of Maryland College Park, 1996. URL http:/l www.isr.umd.edu/ baras/publications/dissertations/1996/96-MS-Shah.pdf

[10] Santosa, B., \& Perwira, R., I., "Computer Network Infrastructure Design and Development using Modern Campus Network Method," Proceeding of research results and services of The Ministry of Research, Technology and Higher Education by Research Institution and Community Service of UPN, Pp. 124-131, ISBN: 978-602-71940-4-5, 2015.

[11] Haimi, A.," "The Influence of Bandwidth Restriction to Network Performance," National Conference of System and Informatics, Bali, Pp. 6, 2011. 
